\title{
Laurence-Moon-Bardet-Biedl Syndrome:A 19 Years Girl with Total Blindness and End Stage Renal Disease
}

MATIUR RAHMAN, ${ }_{-.}^{1}$ NURUL ISLAM, ${ }^{2}$ SARMISTHA BISWAS, ${ }^{3}$ HA ZAVED, ${ }^{4}$ GOURAB DEWAN 5

\begin{abstract}
:
Laurence-Moon-Bardet-Biedl syndrome is a rare autosomal recessive disorder characterized bystructural and functional abnormalities of different organ and tissues. Renal involvement is the single most feature of prognostic importance. We report a case with end stage kidney disease. The diagnosis was missed until patient presented with renal dysfunction. Early diagnosis and screening for renal involvement is crucial for prolong survival.
\end{abstract}

Key words: Consanguinity, polydactyly, total blindness, retinopathy, end stage renal disease.

\section{Introduction:}

Characteristic pentads of LMBBS syndrome are retinitis pigmentosa, polydactyly, obesity, mental retardation, hypogonadism. Some consider renal involvement as sixth component of this disorder. ${ }^{1988}$ Clinical diagnosis is based on the presence of 4 of the 5 cardinal features. ${ }^{2}$ Other clinical features include speech disorder, brachydactyly, developmental delay, polyuria and polydipsia, short stature, ataxia, poor coordination/clumsiness, diabetes mellitus, left ventricular hypertrophy, hepatic fibrosis, and renal hypoplasia /dysplasia. ${ }^{2,}$ 3, 4

Laurence and Moon described retinitis pigmentosa with short stature, hypogonadism among 4 patients in a family in $1866 .^{5}$ Bardet in 1920 observed association of polydactyly and pigmentary retinopathy among some patients with obesity. ${ }^{6}$ Biedl in 1922 described mental retardation in this syndrome. ${ }^{7}$ In 1925 Solis-Cohen and Weiss connected cases described by Bardet and Biedl to the four patients described by Laurence and Moon. ${ }^{8}$

They termed these associations as Laurence- Moon- BardetBeidl syndrome (LMBBS). The original case reported by Laurence and Moon were re-evaluated by Sir J Hutchison in 1900. ${ }^{9}$ Mental retardation and paraplegia were added to original findings by him.

1. Senior House Officer, Dept. of Nephrology United Hospital, Dhaka.

2. Consultant, Dept. of Nephrology, United Hospital, Dhaka.

3. Assistant Professor, Dept. of Medicine, Dhaka Medical College Hospital.

4. Senior House Officer, Dept. of Nephrology United Hospital, Dhaka.

5. FCPS course student, Bangabandhu Sheikh Mujib Medical University, Dhaka.

Correspondence:Dr. MatiurRahman. Senior House Officer, Dept. of Nephrology United Hospital, Dhaka.e-mail: matiur_doc@ yahoo.com.
Amman in 1969 opined Bardet- Biedl syndrome (BBS) is not part of Laurence-Moon syndrome (LMS), rather a distinct entity. ${ }^{10}$ Confusion exists regarding components of two conditions. Common to both condition are pigmentary change in retina, mental retardation and hypogonadism. Spastic paraparesis is a characteristic feature of LMS. ${ }^{11}$ Obesity and postaxial polydactyly is predominant feature of BBS. ${ }^{11-12}$

However there is difference in expression of these syndromes, there is overlap between two in clinical feature and some questioned their distinct identity. ${ }^{12}$ The term LMBBS is still accepted by medical community. As the current patient fulfills almost criteria of both syndromes, for the purpose of this publication, we make no distinction and therefore refer to it as LMBBS throughout.

\section{Case profile:}

A 19 years old young girl presented in nephrology department of United Hospital, Dhaka with symptoms of uraemia and fluid overload.

She was the $4^{\text {th }}$ issue of a consanguineous marriage. She was short in height and obese (Fig.-1). She was born with extra digits in her right hand and left foot (fig-2,3). Her initial motor, mental and other milestone of development was normal. She lost her schooling due to progressive diminution of vision since the age of 8 years and was completely blind at the time of admission. Learning difficulties and intellectual impairments also became evident at the same time. She had five brothers and two sisters. All brothers were alive and healthy, among two; one sister was born with polydactyly in all four limbs and died at the age of 18 months, and other one was of 25 years of age and leading normal life. No relatives were known to have the disease. When family history were explored it was unremarkable in previous generations as far as could be traced. 


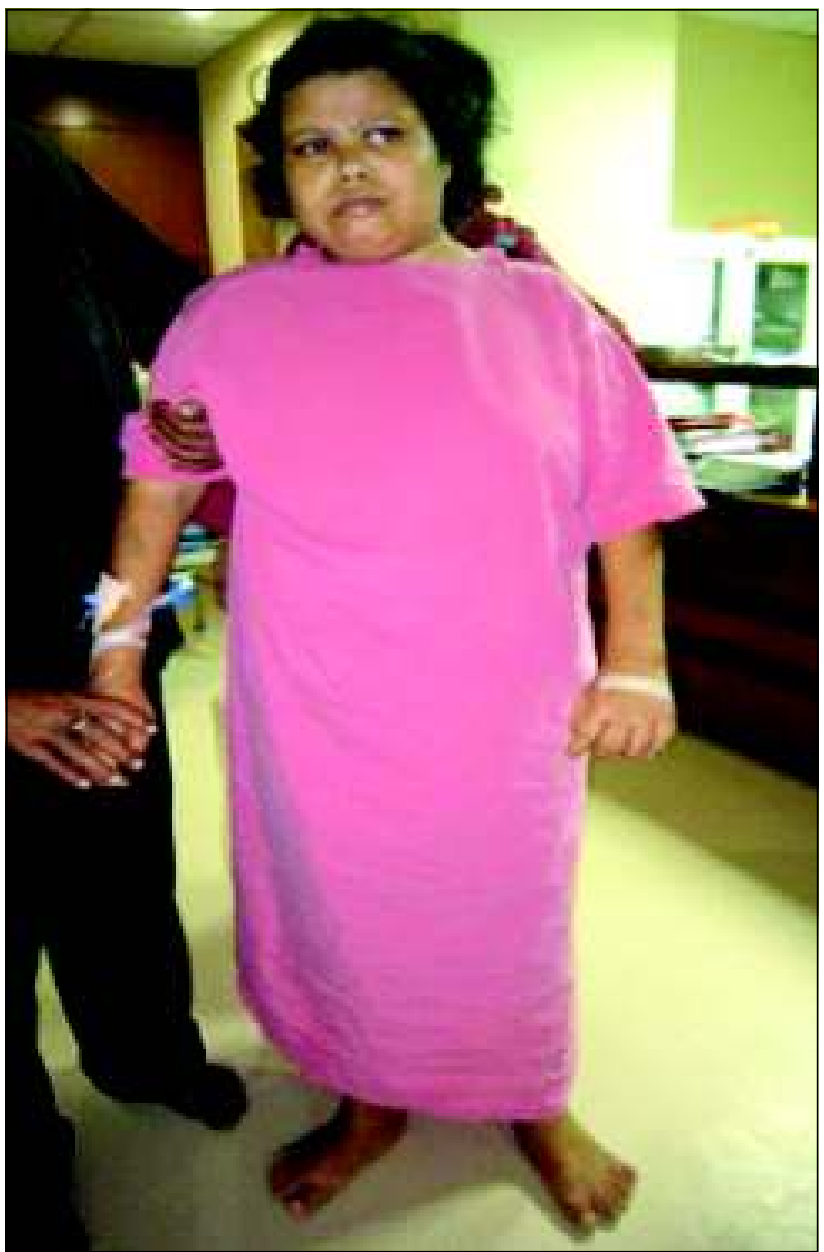

Fig.-1: Short and Obese

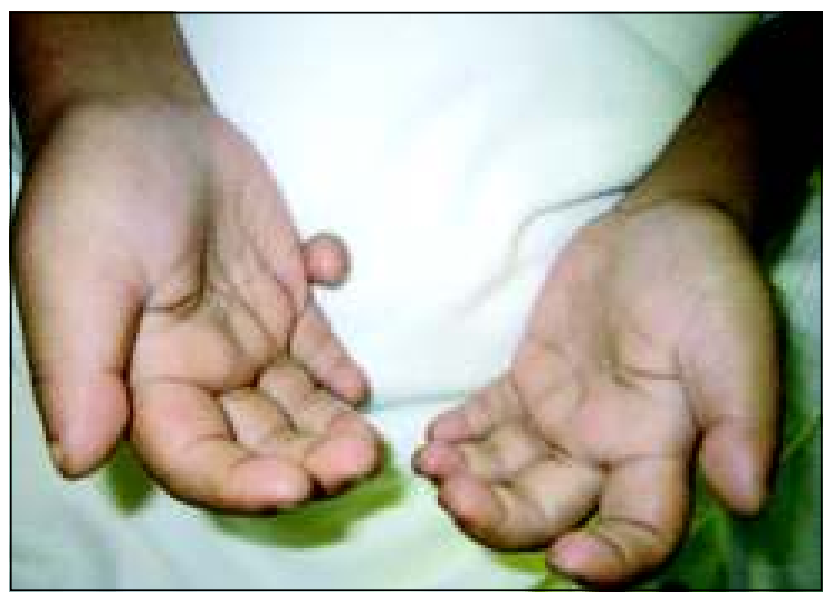

Fig.-2: Polydactyly (Right hand)

On examination, she was found to be obese (BMI: $33.3 \mathrm{~kg} /$ $\mathrm{m}^{2}$ ) (Ht-1.45 m, wt-70 kg) of truncal type, short statured. There was generalized edema with crackles in both lung fields with normal precordium. The blood pressure was $140 / 80 \mathrm{~mm}$ of $\mathrm{Hg}$ with regular pulse and normal jugular venous pressure.

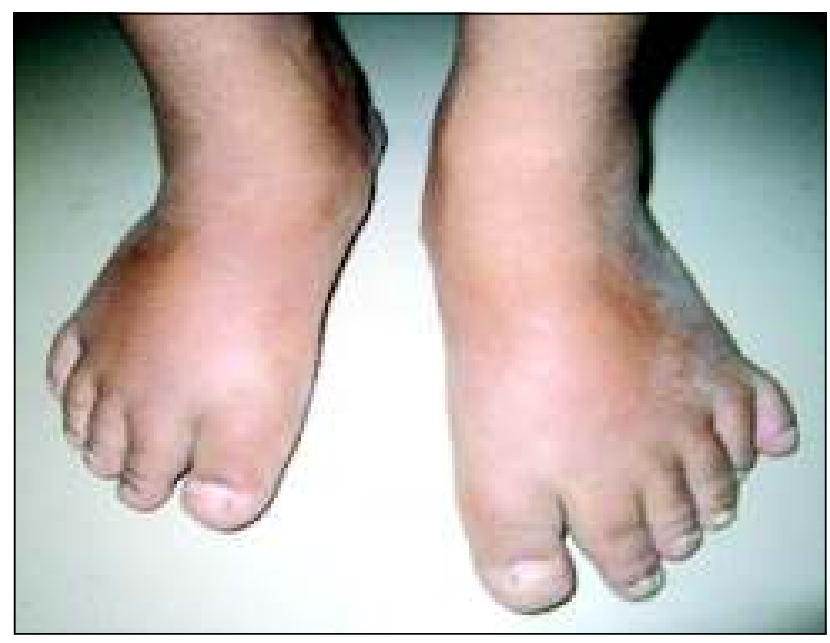

Fig.-3: Polydactyly (Left foot)

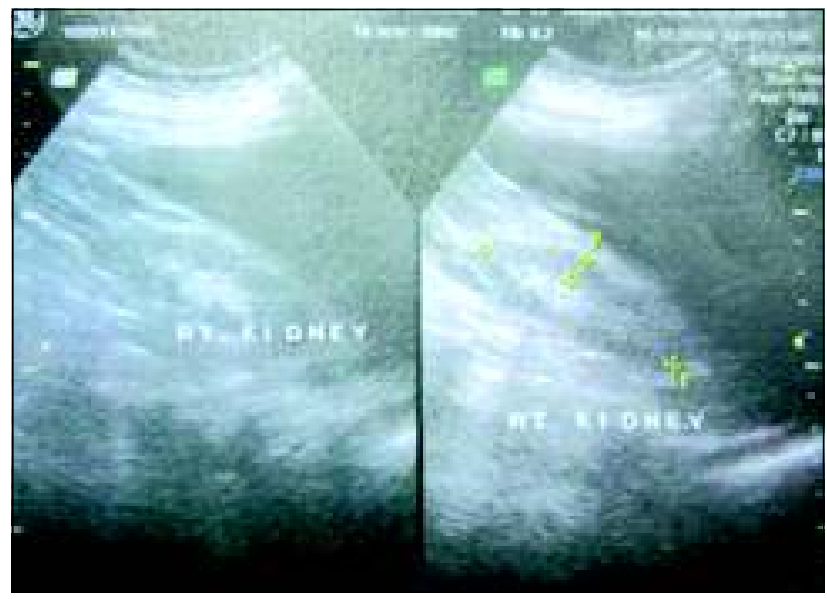

Fig.-4: Ultrasound of both kidneys

Features of uraemia like-drowsiness, twitching of muscles in different part of body, myoclonus was present. Exaggerated reflexes, bilateral planter extensor response and Hoffman's sign were positive.

Investigations revealed hemoglobin of $9.6 \mathrm{gm} / \mathrm{dl}$, blood urea $153 \mathrm{mg} / \mathrm{dl}$ (Normal $15-45 \mathrm{mg} / \mathrm{dl}$ ) and serum creatinine was 7.2 $\mathrm{mg} / \mathrm{dl}$ (Normal $0.6-1.5 \mathrm{mg} / \mathrm{dl}$ ). sodium $140 \mathrm{mmol} / \mathrm{l}$, potassium $8 \mathrm{mmol} / 1$, chloride $99 \mathrm{mmol} / \mathrm{l}$. Ultrasonography revealed both kidneys smaller in size, measuring 71X 53mm (right kidney) and $72 \times 51 \mathrm{~mm}$ (left kidney), parenchymal thickness of RK is $9 \mathrm{~mm}$ and $\mathrm{LK}$ is $8 \mathrm{~mm}$, increased cortical echogenicicty with poor cortex and medulla differentiation (fig-4). Patient's party refused to do renal biopsy. ECG, Echocardiography, EEG and CT scan brain were normal.

Subsequently she was put on haemodialysis. After recovery from ureamic encephalopathy it was found she had no perception of light in both eyes, and bilateral gaze-evoked nystagmus was present.Ophthalmoscopic examination 
showed bilateral optic atrophy and diffuse hypo and hyperpigmentation sparing the macular area, as well as bone spicules in the mid peripheral retina (retinitis pigmentosa). Her IQ was low $(<60)$ and secondary sexual characters were not well developed.

She was advised maintenance haemodialysis before successful renal transplantation done. She underwent maintenance dialysis in her native place. Patient died following missed periods of dialysis 6 month after diagnosis.

\section{Discussion:}

LMBBS is autosomal recessive disorder.Some genetic linkage on certain chromosome has been found but their role is yet to be fully known. Interfamilial marriage is another risk factor. LMBBS affects approximately 1 in 100,000 babies born. The Bedouins of Kuwait and Newfouland area has high prevalence. $^{13}$

Our patient was also born of a consanguineous wedlock. Probably her sister which died at early age was also affected. And cases showed different members being affected in a single family. Earlier reports of Laurence and Moon, Biedl described affection of several siblings.

Because of diverse systemic involvement it can present to any specialty. In two previously reported cases in Bangladesh one presented to ophthalmology unit with night blindness and other to medicine unit. ${ }^{14-15}$ While these two cases were male our patient was female and diagnosed late probably because of rare occurrence of the disease. Such delayed diagnosis until patient presenting with end stage renal disorder was documented by other observers. ${ }^{1}$

Only in the last 20 years significant renal abnormality has been reported with this syndrome. Urologic abnormality has been reported in $90 \%$ patients with normal renal function.A significant number of patients (30\%) develop symptoms or signs of renal disease ranging from recurrent urinary tract infections (associated with reflux) to chronic renal failure. Renal tubular dysfunction is also common. ${ }^{1} \mathrm{~A}$ report suggested incidence of ESRD as $4 \%$ in LMBBS. $^{15}$

Renal involvement is the prognostically most significant. ${ }^{\mathrm{c}}$ though incidence is low, presence of ESRD defines prognosis of individual. Death from ESRD usually observed in third or fourth decade. ${ }^{1}$ Upto 2007 only 8 cases were described in Indian literature with only one having ESRD. ${ }^{16}$ So far we could find two reported case in Bangladesh but none had renal involvement. ${ }^{14-15}$

As patient's party denied renal biopsy; exact histological nature of renal involvement remained undetermined. Chronic interstitial nephritis, mesangial proliferative glomerulopathy, and ultrastructural changes in the glomerular basement membrane has been described in various reports. ${ }^{15}$

Management of BBS is supportive and includes training and rehabilitation for blind and mentally retarded patients, hearing aids for deafness, and diet and exercise for obesity. Surgical correction can be undertaken for polydactyly. Organizations can provide emotional and social support and help in all-round development. Early and regular screening for hypertension, diabetes, and renal involvement is required. ${ }^{10}$ The management of renal failure does not differ from that due to any other cause. All modalities of long-term renal replacement therapy, i.e., dialysis, and renal transplantation can be offered to these individuals. ${ }^{15}$

\section{Conclusion:}

We described a case of LMBBS with end stage renal disease. Renal failure being the commonest cause of death in this condition. However supportive management can prolong the survival. The diagnosis should be considered in patients with characteristic phenotypes. Early and regular screening for hypertension, diabetes, and renal involvement is required.

\section{Conflict of Interest : None}

\section{References:}

1. Bryan Williams, David Jenkins and John Walls.Chronic renal failure; an important feature of theLaurence-Moon-Biedl syndrome. Postgraduate Medical Journal (1988) 64, 462-464

2. Yamada K,MiuraM, Miyayama H, Sakashita N, KochiM, UshioY Diffuse brain stem glioma in a patient with LMBBS. PadiatrNeurosurg 2000 Dec; 33(6):327-7

3. Urban SL, aughRF, Otolaryngologic feature of LMBBsysndrome. Otolaryngol Head Neck Surg 1999April; 120(4):571-5

4. Ukar B, Yakut K,Kurul N, Buyukasik F, Vardareli E .Renal involvement in LMBB syndrome. PediatrNephrol $1997 \mathrm{Feb}$; 11(1):31-5

5. Laurence Jz, Moon RC..Four cases of retinitis pigmentosa occurring in the same family and accompanied bygeneral imperfection of development.Ophthal Rev 1866; 2: 32-41.

6. BardetG. Sur un syndrome d'obésitécongénitale avec polydactylie et rétinitepigmentaire (contribution àl'etudedesformescliniques de l'obésitehypophysaire). Thése de Paris 1920 (no170): 107.

7. BiedlA.Eingeschwisterpaarmitadioposo-genitalerdystrophie. Dtsch Med Wschr 1922; 48:1630.

8. Solis-Cohen S., Weiss E..Dystrophiaadopogenitalis with atypical retinitis pigmentosaand mental deficiency: the Laurence-Biedl syndrome a report of four cases in one family. Am J Med Sci 1925; 169: 489-505. 
9. Hutchinson J.. Slowly progressive paraplegia and disease of the choroids with defective intellect and arrested sexual development. Arch Surg 1900; 11: 118-122

10. Ammann F. Investigations cliniquesetge'netiquessur le syndrome de Bardet-Biedl en Suisse. J Genet Hum 1970; $18: 1-310$

11. Tariq Q, Ayub, Nasti AR, Ashai M. Laurence Moon(Bardet) Biedl syndrome ; nystagmus is additional feature, JKpractitioner 2003;10(3):217-218

12. Green JS, Parfrey PS, Harnett JD et al. The cardinal manifestations of Bardet-Biedl syndrome, a form ofLaurenceMoon-Biedl syndrome. N Engl J Med 1989; 321:1002-1009.

13. Butt HA, Zahra SS . A very rare genetic disease Laurence Moon BardetBeidle syndrome and substandard pharmaceutical care provision to the patient and improper therapy and monitoring; a case report Canadian Journal of Applied Sciences2012;2(2): 260-266

14. Habibullah M, MohiuddinAA.Bardet-Biedlsyndrome. Mymensingh Med J. 2009 Jan; 18(1):80-3.

15. Abdullah AB, Niloy AA, Shah TA, Biswas SK, Imran AK, Murshed KM, Ahmed M.Laurence Moon Bardet Biedl Syndrome. Mymensingh Med J. 2009 Jan; 18(1 Suppl): S124-128.

16. Rathi M, Ganguli A, Singh SK, Kohli HS, Gupta KL, Sakhuja $\mathrm{V}$, JhaV.Bardet-Biedl syndrome with end-stage kidney disease: A case report and review of literature. Indian $\mathrm{J}$ Nephrol 2007; 17:10-3. 